Cambridge Archaeological Journal

http://journals.cambridge.org/CAJ

CAMBRIDCI

ARCHAEOLOGICAL

Additional services for Cambridge Archaeological Journal:

Email alerts: Click here

Subscriptions: Click here

Commercial reprints: $\underline{\text { Click here }}$

Terms of use : $\underline{\text { Click here }}$

\title{
Stone Tools and the Linguistic Capabilities of Earlier Hominids
}

James Steele, Angus Quinlan and Francis Wenban-Smith

Cambridge Archaeological Journal / Volume 5 / Issue 02 / October 1995, pp 245 - 256 DOI: 10.1017/S0959774300015043, Published online: 14 October 2009

Link to this article: http://journals.cambridge.org/abstract S0959774300015043

How to cite this article:

James Steele, Angus Quinlan and Francis Wenban-Smith (1995). Stone Tools and the Linguistic Capabilities of Earlier Hominids. Cambridge Archaeological Journal, 5, pp 245-256 doi:10.1017/S0959774300015043

Request Permissions : $\underline{\text { Click here }}$ 


\title{
Stone Tools and the Linguistic Capabilities of Earlier Hominids
}

\author{
James Steele, Angus Quinlan \& Francis Wenban-Smith
}

The evolution of human manipulative abilities may be clearly linked to the evolution of speech motor control. Both creativity and complexity in vocal and manipulative gestures may be closely linked to a single dimension of brain evolution - the evolution of absolute brain size. Inferring the linguistic capabilities of earlier hominids from their lithic artefacts, however, required us to take account of domain-specific constraints on manipulative skill. In this article we report on a pilot flint-knapping experiment designed to identify such constraints 'in action'.

When did our ancestors first acquire a modern linguistic ability? What forms of protolinguistic communication were used by the hominids who came before or by those who evolved divergently from that evolutionary path? These questions continue to fuel one of the core areas of research in Palaeolithic archaeology and palaeoanthropology. Some earlier issues, however, have now been resolved, and it is important to build on these concrete foundations if our understanding is to progress.

The appearance of a human-like language capacity in earlier hominids depended on at least three independent sets of preconditions. First, the cognitive and motor complexity of language organization demanded increased processing capacity in the brain. This may also have involved reorganization of the speech centres at the top level of speech-motor and auditory processing areas. Secondly, the spoken nature of normal human language demanded a vocal tract morphology capable of generating those complex patterns of rapid acoustic energy modulation which constitute the speech signal. Thirdly, the cooperative nature of information exchange in human speech demanded a stable structure of social relationships which permitted the evolution of this specific form of 'reciprocal altruism'. Research falls into one of at least three categories, according to which of these three preconditions is being investigated.

In this article we argue that the controversy relating to one such precondition - that of the evo- lution of major structural features of the human brain relating to language ability - is' close to being resolved, and that this provides us with a foundation for modelling the behavioural ability of protohuman hominids. We argue that a subordinate issue, the relationship between stone tool-making skills and linguistic production abilities, is also close to being resolved; and we outline some methodology for advancing further towards this end.

Comparing central nervous systems of human and living non-human primates

\section{Evolution of brain size and circuitry}

If we want to reconstruct the brain structure of hominids then we need to look not just at endocasts, but also at the soft-tissue brain structure of primates related in differing degrees to ourselves. Two scenarios of human brain evolution have recently competed for favour. The choice is between 1) the appearance of new circuits and the enlargement of specific divisions of the neocortex in a process of mosaic reorganization, and 2) the enlargement of a general-purpose computer capable of underwriting complex and flexible adaptations in a variety of domains. Proponents of the 'reorganization' account (e.g. Holloway 1983) have focused on the development of cerebral asymmetry and of the speech areas. Proponents of the 'encephalization' account (e.g. Jerison 1988) have focused on sheer neural processing 


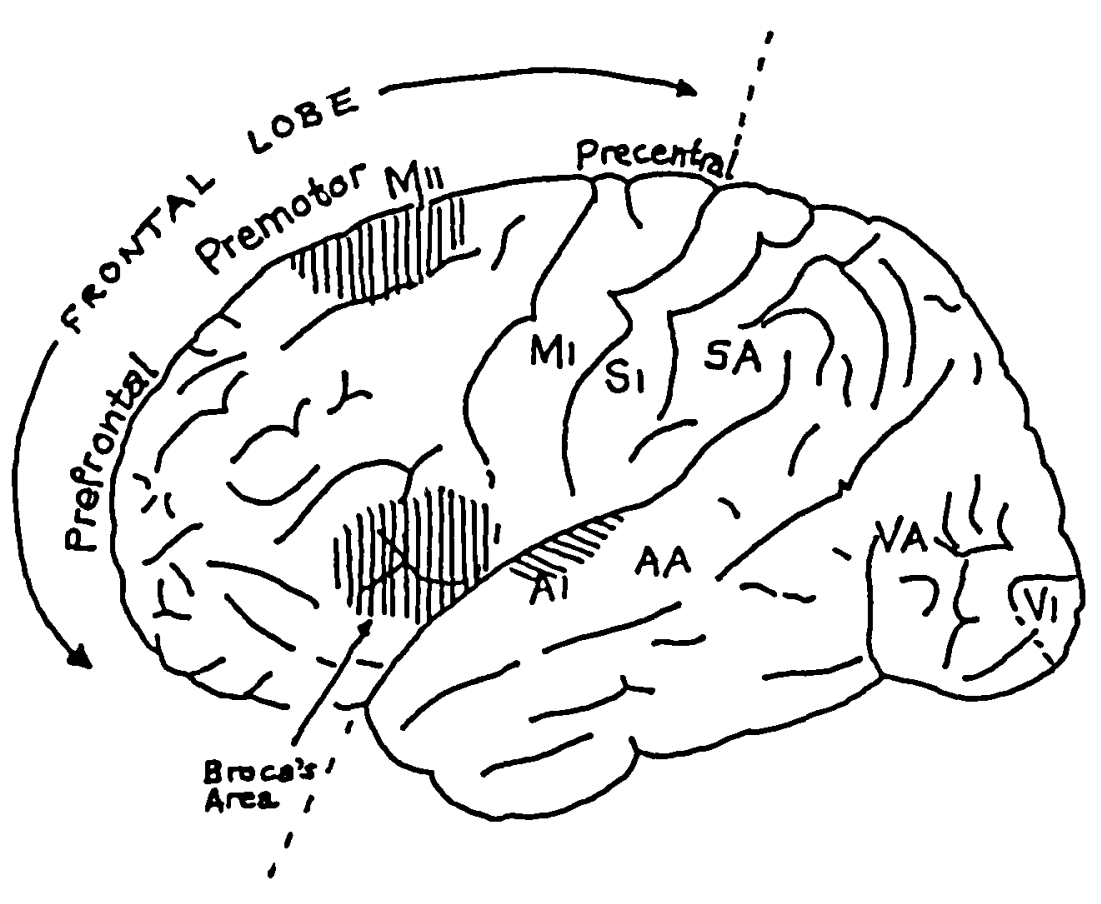

Figure 1. Schematic dingram of some major subdivisions of the human cerebral cortex, lateral vietu.

resource, perhaps without giving due attention to the functional specialization of different areas and their involvement in dedicated circuitry pertaining to the several sensory modalities. Some accommodation between the two approaches seems necessary namely, a recognition that the human brain shares with other primate brains some dedicated circuitry, and a formal understanding of the difference made by proportional variation in the neural resources involved in computations involving these circuits. The study of circuitry is specific to neuroanatomists. The analysis of gross quantitative variation in neural resources, however, falls within the more general area of allometry (the study of scaling relations between correlated dimensions either of an organism, or of an organism and its ecological niche).

Deacon (1988) has shown that the basic circuitry involved in human speech processing appears to be homologous with that in the macaque brain. It must thus be a conserved feature shared with a remote Old World anthropoid common ancestor. According to Preuss $(1995,1237)$ :

connectional and microstimulation studies in nonhuman primates indicate that PMV [the ventral premotor area, the Broca's area homologue] represents forelimb and orofacial movements ... Metabolic and surface stimulation studies in humans suggest that Broca's area also represents nonlinguistic forelimb and orofacial movements ... Results such as these have led Fox and colleagues (1988) to suggest that Broca's area is a general premotor area without specific linguistic function.

These findings are leading some researchers to make more confident predictions about the relationships between linguistic and manipulative behaviour, and their evolution in hominids (Greenfield 1991; Wilkins \& Wakefield 1995).

Passingham (1982) examined the available data on the organization of human and primate brains, and concluded that the human brain is subject to the same scaling rules as that of other primate brains that is, we have the brain organization, and the proportions among major brain structures, which would be expected of a primate of our absolute brain size. A related conclusion, and one bearing on the interpretation of hominid endocasts, has been reached by Armstrong et al. (1993) with respect to cortical folding and brain expansion. They argue that the pattern of convolutions on the brain surface evolved in Homo in parallel with brain expansion, and not before it. It is important to note that these scaling relations are telling us about the extent to which the human brain and its components are built by developmental rules similar to those obeyed in other primates. Functionally, we must differentiate the brains and cognitive abilities of primate species on the basis of actual proportions of these various structures, and of their absolute dimensions as neural networks (Passingham et al. 1986).

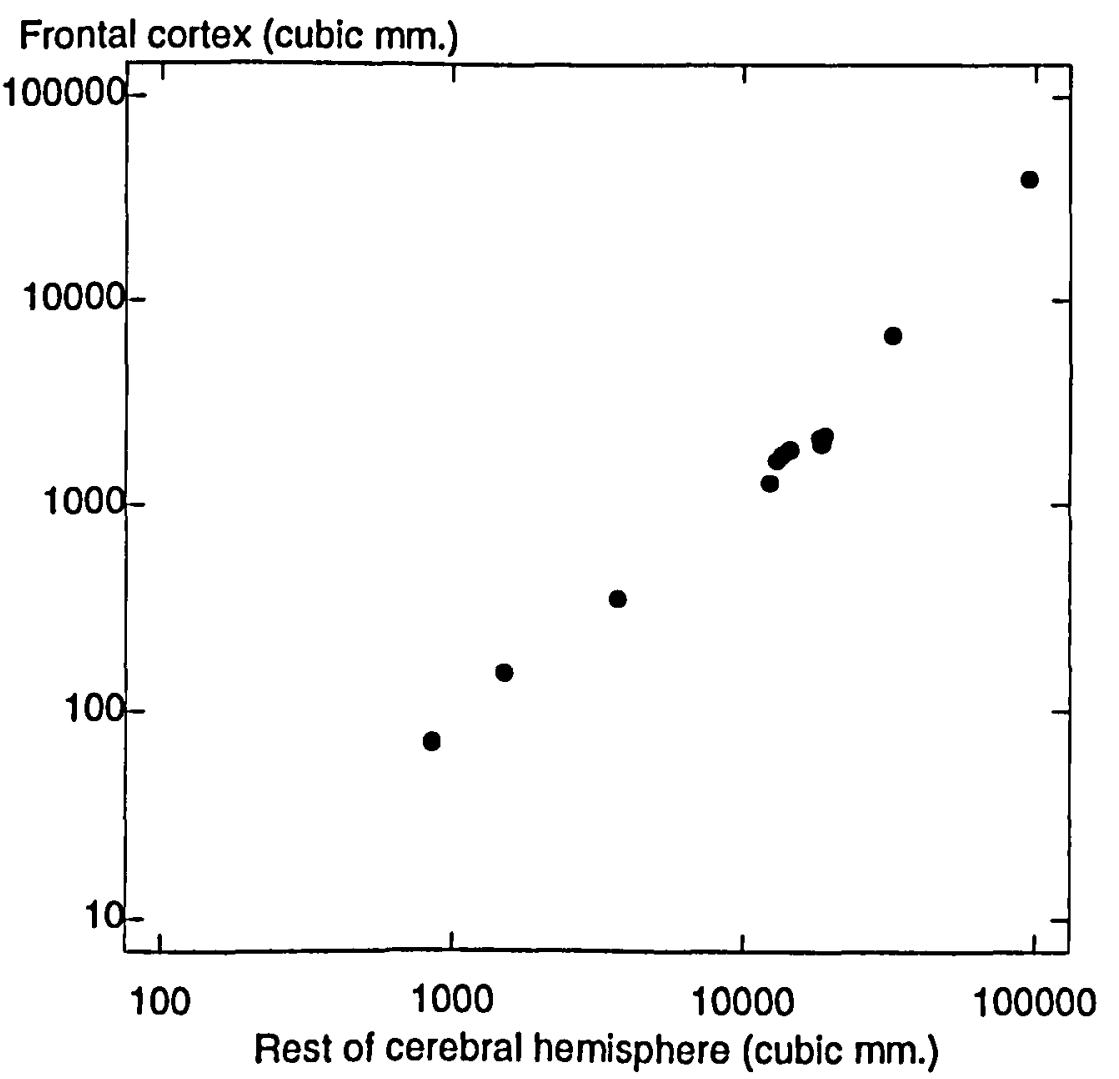

Reduced Major Axis equation:

$$
\begin{gathered}
\text { Ln (frontal volume, } \left.\mathrm{mm}^{3}\right)=1.28(\text { ln rest of cerebral } \\
\text { hemisphere, } \left.\mathrm{mm}^{3}\right)-4.63 . \mathrm{R}^{2}=0.97 \text {. }
\end{gathered}
$$

Figure 2. Scaling relationship of the prefrontal area to the rest of the cerebral hemisphere in humans and other primates. (Data from Brodmann 1912, reproduced by Markowitsch 1988.) 
Table 1. Two theoretical models of prefrontal function in humans, one from clinical neuropsychology and the other from Goldman-Rakic's monkey model. (Derived from Daigneault et al. 1992.)

\section{NEUROPSYCHOLOGICAL MODEL:}

-Planning (or the elaboration of strategy) and execution of sequences of planned responses;

- Self-regulation of behaviour in response to environmental contingencies (including one's own errors);

-Maintenance of a nonautomatic cognitive or behavioural set;

- Spontaneity/sustained mental productivity;

-Spatiotemporal segmentation and organization of events.

\section{GOLDMAN-RAKIC'S MONKEY-BASED MODEL:}

-Regulation of manual responses by verbal prefrontal representational memory;

-Regulation of verbal responses by verbal prefrontal representational memory;

-Regulation of manual responses by prefrontal visuospatial representational memory;

-Regulation of simple responses by prefrontal visuospatial representational memory.

\section{Evolution of neocortical function}

These scaling studies extend to variation in the proportions of neocortex dedicated to different processing tasks across the primate order.

Hominid brain evolution has involved an increasing role for the prefrontal area of the frontal lobes in the neocortex - a trend which appears to be a function of change in the absolute size of the brain across primate species, as indicated by the slope of the regression (Fig. 2).

Table 1 summarizes two theoretical models of human prefrontal function, one deriving from human clinical neuropsychology and the other from monkey research. Both emphasize the role of this area in regulating behaviour by internal representations when there is no immediate feedback from environmental contingencies; and this is also the conclusion of Ingvar's (1994) review of PET scan studies. The prefrontal mechanisms

\begin{abstract}
appear to be responsible for the inner representations, ideas, plans, expectations and visions which form an integral part of the phenomenon of will. Apparently, such representations are related to activity in neuronal networks which guide the production of, and produce the programs for, future willed motor acts, language expressions, cognitive activity, and a goal-directed behaviour. (Ingvar 1994, 11)
\end{abstract}

In planning tasks similar to those in tool-making ( $c f$. the phasing of lithic reduction sequences identified by Bradley \& Sampson 1986), we may note that humans with frontal lobe damage have been found to exhibit impairments in the ability to sequence events - 'patients with frontal lobe damage were impaired in planning a sequence of moves that would rearrange an initial pattern of colored beads into a goal state. Efficient performance on this task depends on the ability to break the task into subgoals and then reach each of the subgoals' (Robin \& Holyoak 1995, 994).

In summary, the trend for disproportionately increased prefrontal cortex with increases in absolute brain size, across the primates, would be expected to correlate in hominids of varying brain sizes with differences in capability for planning and execution of complex sequential actions regulated by mental representations rather than immediate environmental contingencies: this would have applied both to tool-making and to actual linguistic practice.

Similar scaling effects have influenced the evolution of functional lateralization. Neocortical evolution in hominids has involved increasing lateral specialization of the two cerebral hemispheres, but this appears to relate to processing inefficiencies in larger brains where there is bilateral involvement (Ringo 1991; Ringo et al. 1994): thus there are also indications that some gross cerebral asymmetries are more pronounced in pongids than in monkeys, presumably due to the larger cortices of the hominoid species (de Lacoste \& Woodward 1988, 322).

McHenry (1994) has summarized estimates of body weight and brain volume in hominids, and their relative proportions (Table 2). It is evident from this that whereas absolute brain size increases markedly between Homo habilis and early Homo erectus, the same cannot be said for the size of the brain relative to the size of the body. Homo erectus had already reached the body size of modern humans. We have seen that cognitive evolution is fundamentally linked in primates to the absolute size of the brain. One point worth making here is that while the increase in absolute brain size in modern humans will have been reflected in increased cognitive abilities such as those related to prefrontal functions, the 
second, and perhaps more marked contrast with early Homo erectus (increase in relative brain size) can only have affected behaviour through evolved 'personality'-type effects of the different proportions of total metabolic energy allocated to brain function in the two species. One can see this to some degree in the living great apes. Studies differentiating the great ape species by temperament date from at least the Yerkes' day (Yerkes \& Yerkes 1929). The Yerkes found gorillas to be diffident and shy, orangutans withdrawn and brooding, and chimpanzees outgoing, expressive and impulsive (Clarke \& Boinski forthcoming). Such contrasts in cognitive style are most likely a reflection of the proportion of metabolic energy allocated to the brain, as opposed to other 'expensive' tissues, such as the gut, in these species (Steele in press).

\section{Cognition, modularity and the use of stone tools as indicators of linguistic abilities}

Research on the evolution of tool-making and toolusing abilities can be subdivided into a number of categories, analogous to those listed above for speech evolution. Attention may focus on the central nervous system and cognitive or neuromotor programming; on the peripheral adaptation to manipulative ability, specifically the evolution of the hominid hand; or on the social preconditions for the cultural evolution of traditions.

The premise of work on artefact traditions as language indicators is that there is some commonality of cognitive operations in the two domains. Isaac (1976) itemized cognitive aspects of stone tool assemblages which may indicate linguistic ability (symmetry, multistage core preparation techniques, and finally the construction of multi-component tools such as hafting). Gowlett (1986, 258) discussed conceptualization and operational chains in the production of Lower Palaeolithic artefacts. He noted that 'the unitary approach to human abilities would suggest that the complexity of abilities seen in one field would probably extend across the range of human abilities'. Measuring the cognitive complexity of stone tool production has received additional impetus from Wynn's work on the conceptual structure of tool production (e.g. 1989; 1991) and from work by Pelegrin and others in France on the chaine opératoire (Pelegrin 1990; Bril 1991; Roux et al. 1995). Wynn (1991) proposes that early Acheulean bifaces represented a new level of intelligence in their makers. Their manufacture to a symmetrical standard form demanded an abstract representation of the tool type which incorporated a hierarchy of subelements pertaining to edge configuration, weight, material and knapping procedures. Pelegrin (1990) argues similarly that 'elaborate knapping activity' appeared only with the Acheulean tradition, with symmetry in bifaces and standardization of the debitage. It involved a hierarchy of subassemblies of motor gestures and a role both for procedural memory and declarative (conceptual) memory. However, we need to get a clearer picture of the nature of the mental workload involved in tool production, however, if we are to take this synthesis further. That will require some experimental studies of modern knappers in controlled conditions (see below).

We should, however, note some problems. It is increasingly common for cognitive psychologists to suggest that human mental processes are, at some level or series of levels, domain-specific. What is meant by this is that many human cognitive abilities appear to be specialized to deal with specific types of information (Hirschfeld \& Gelman 1994). This dis-

Table 2. Species of hominid with estimated body zueights, brain volumes, and relative brain sizes (EQ). (After McHenry 1994, trule 1.)

$\begin{array}{lccccc}\text { Species } & \begin{array}{c}\text { Dates, } \\ \text { Myr }\end{array} & \begin{array}{c}\text { Body weight, } \mathbf{k g} \\ \text { (male) }\end{array} & \begin{array}{c}\text { Body weight, } \mathbf{k g} \\ \text { (female) }\end{array} & \begin{array}{c}\text { Brain volume, } \\ \mathbf{c m}^{\mathbf{3}}\end{array} & \text { E.Q. } \\ \text { A. nfarensis } & 4-2.8 & 45 & 29 & 384 & 2.2 \\ \text { A. nfricantus } & 3-2.3 & 41 & 30 & 420 & 2.5 \\ \text { A. nethiopicus } & 2.7-2.3 & & & 399 & \\ \text { A. boisei } & 2.1-1.3 & 49 & 34 & 488 & 2.6 \\ \text { A. robustus } & 1.8-1.0 & 40 & 32 & 502 & 2.9 \\ \text { H. habilis } & 2.4-1.6 & 52 & 32 & 597 & 3.1 \\ \text { Early H. erectus } & 1.8-1.5 & 58 & 52 & 804 & 3.3 \\ \text { Late H. erectus } & 0.5-0.3 & 60 & 55 & 980 & 4.0 \\ \text { H. sapiens } & 0.4-0.0 & 58 & 49 & 1350 & 5.8\end{array}$


sociation between domains has been applied to the relationship between language and spatial cognition (Bellugi et al. 1991), and to the relationship between language and motor control (Pinker \& Bloom 1990). The evidence for some degree of dissociation between ability in different domains, notably language development and other areas of cognitive development, has become increasingly difficult to ignore. Cromer, an early advocate of the 'cognition hypothesis' of language acquisition ('we are able to understand and productively to use particular linguistic structures only when our cognitive abilities enable us to do so': Cromer 1974 reprinted in 1991, 54), later came to suspect on the basis of clinical evidence that language acquisition was dissociable from general cognitive development (1991, 55-141). This type of evidence has also led Thomas Wynn, an authority on the cognitive demands of hominid stone tool production, to argue that 'We cannot use stone tools or pots as evidence for grammatical rules of any kind' (1991, 198).

We have already seen that the ancestral homologue of Broca's area may subserve linguistic and manipulative functions. It is important to understand that clinical and experimental evidence for more specific, dissociable cognitive domains in human subjects does not necessarily mean that the hardware enabling each class of behaviour has evolved separately, in a mosaic fashion, as a response in each case to a specific suite of selective pressures. On the con-

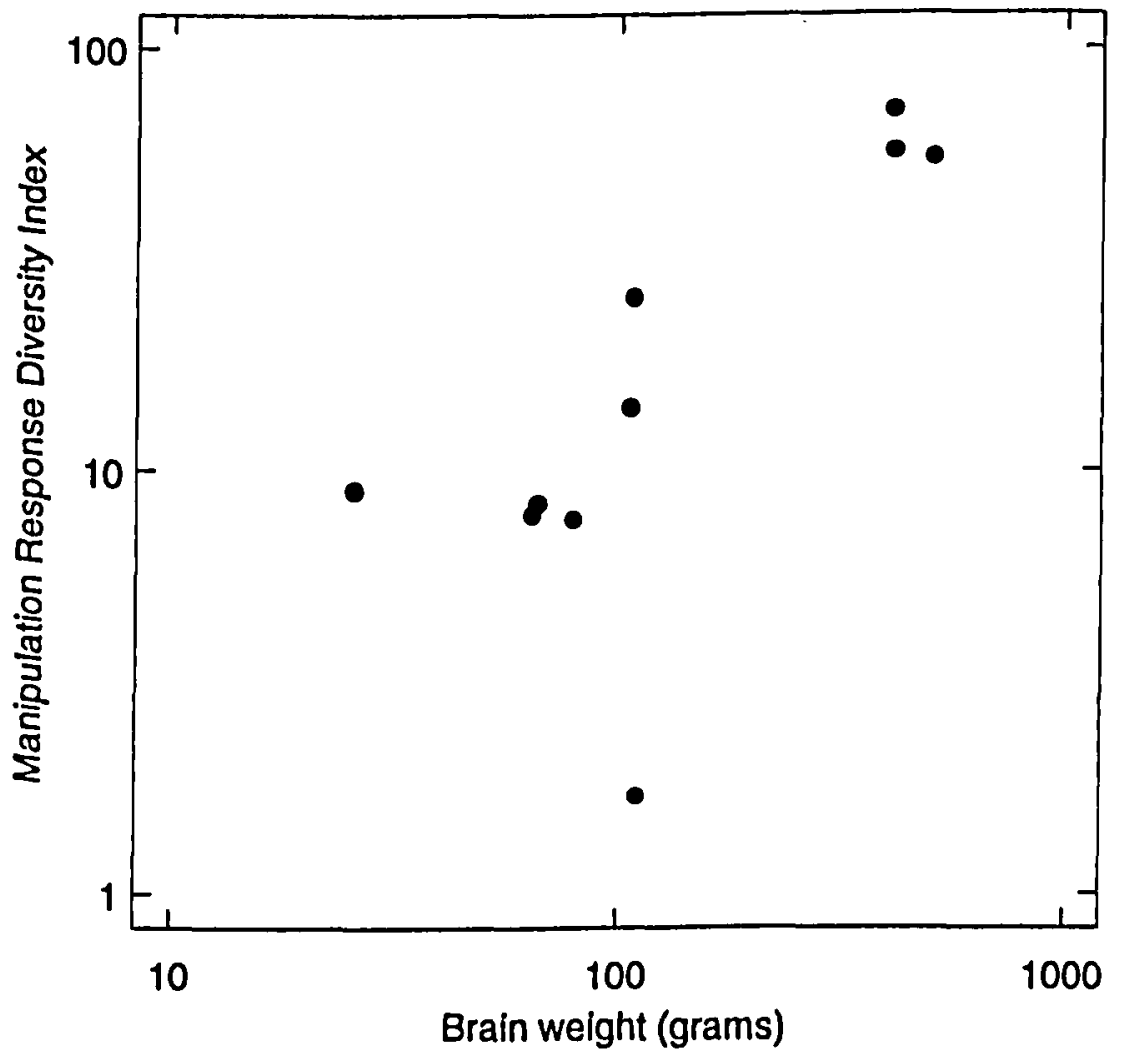

Figure 3. Adult brain size and manipulative creativity the latter in a captive sample - of nonhuman primate genera. (Data from Parker 1974 and Harvey et al. 1987). trary, it seems more probable that separate, parallel brain circuits exist, subserving cognition and performance in separate domains of ability or skill. Each of these, however, is likely to be subject to overall domain-general constraints on long-term memory storage, on working memory capacity, and on the simultaneous allocation of attention and cerebral metabolic energy to the various components of any complex mental task. Gibson (1990) argues that in species-level comparisons, greater intelligence corresponds to more hierarchical complexity in the coordination of differentiated elementary abilities. This may be supported by the correlation between the amount of combinatorial creativity seen in object manipulation tasks in primates, and their speciestypical adult brain weights (Fig. 3: from Parker 1974 and Harvey et al. 1987). ${ }^{1}$ It is also supported by the recent analysis of Finlay \& Darlington (1995), who found-that neocortical expansion is linked to absolute brain size increase across various orders of mammals. They also cite work indicating that in mammals, 'the amount of cortex devoted to forelimb control can increase only as the result of an apparently inefficient increase in total cortex volume' $(1995,1578$, citing Nudo \& Masterson 1990). Indeed, Finlay \& Darlington conclude from their own results that in hominid evolution 'the highly conserved sequence of events in neurogenesis provides a reason why selection for any one ability might cause, in parallel, greater processing capacity for all the others' (1995, 1583).

The frontal lobes of the primate brain are involved in regulating parallel circuitry for auditory, visual and somatosensory information, and movement of the vocal cords, eyes and limbs (Passingham 1987; Yeterian \& Pandya 1988). Annett (1993) notes that verbal and motor learning are neurologically dissociable, but that motor imagery (which is implicated in the control of motor output) appears to be evoked when the supplementary motor area of the frontal cortex is activated. There is also evidence of prefrontal involvement in working memory aspects of motor tasks (Ingvar 1994). Goldman-Rakic proposes that for motor control, the prefrontal areas are 'essential for the initiation, selection and guidance of behaviour by representational knowledge, and they might accomplish this regulation by enhancing or inhibiting responses mediated by "lower" centres' [including the supplementary motor area] $(1987,188)$. Goldman-Rakic notes also that in contrast to the supplementary motor area (SMA), the prefrontal system 'has access to the spatial map represented in the posterior parietal cortex and is not tied to any single 
output modality, i.e. any single muscle group. This gives it the potential to regulate the responses of any part of the upper body, head, mouth and eyes so as to react or not when environmental contingencies arise' $(1987,195)$.

Spatial cognition appears, moreover, to be dissociable from language processes since underlying factors produce more general contrasts in processing between the two cerebral hemispheres. Deficits in non-linguistic visuospatial cognition are associated with lesions in the right hemisphere, and linguistic deficits (in both spoken language and ASL) are associated with left hemisphere damage. Left hemisphere damage affects other aspects of tool production and use which have closer parallels with the serial order of linguistic syntax. In general, left hemisphere damage is associated with deficits in motor tasks involving movement control in the absence of sensory feedback, and with deficits in production of rapidly sequenced movements (Haaland \& Harrington 1994). Ideational apraxia - a deficit in conceptual knowledge relating to tool use - is associated with damage to supramodal association areas of the dominant hemisphere, and may occur independently of linguistic deficits. This suggests that motor control may involve an autonomous 'action semantics' which parallels linguistic semantics (Ochipa et al. 1989; 1992; De Renzi \& Lucchelli 1988). In summary, dissociation of cognitive domains seen in clinical syndromes where linguistic and visuospatial abilities are differentially affected may relate to general contrasts in processing style between the two cerebral hemispheres, and not to specific behavioural contrasts between language and tool use. Furthermore, a role for the left hemisphere in conceptual structuring and motor sequencing of both tool use and language is indicated by the clinical evidence of patients with ideational apraxia and linguistic aphasia. ${ }^{2}$

There are also a number of contrasts in the peripheral organization of language and manual actions which need to be taken into account if we are interested in general constraints of central processing resources on both domains. Pinker \& Bloom (1990, 726) suggest that motor control 'is a game of inches so its control programs must have open continuous parameters for time and space at every level of organization'. They contrast this with the stability of grammatical rules in linguistic production. Linguistic utterances are targeted at a receiver, and the length of a sentence is constrained by the working memory limits of the receiver in parsing this input and extracting its conceptual meaning. The need for economy in verbal output will inevitably constrain syntactical rules in a way which is not applicable to motor sequencing in tool-related activity. In tool production and use, the sheer length of time (and working memory load) involved in organizing a single motor action within the chain that makes a production sequence may mean that such sequences are always learnt as 'strings of beads'.

We should also note that in modern humans, linguistic production and object manipulation tasks are partially dissociable in terms of the mental workload required in each domain to produce output of a given level of complexity. The difference is due to musculoskeletal and environmental variables. Linguistic production involves low-energy vocal tract modulations; furthermore, the proximity of the vocal tract to the cognitive centres of the brain means that nerve impulses to and from this tract form a feedback loop with a much shorter conduction time than those involving the hand and arm. This inevitably affects the complexity of fine motor tasks which can be co-ordinated by the brain when feedback regulation of motor output is involved. Additionally, the contrast between the medium of vocal communication (acoustic modulation of air pressure) and that of object manipulation (moving and modifying the spatial arrangements and properties of objects using limb segments of nontrivial size, mass and inertia) introduces constraints on the temporal resolution of manual tasks which do not apply in speech output. These constraints arise from the greater resistances to movement in manipulative tasks. If we are to compare cognitive factors - specifically, the hierarchical organization and mental workload involved in linguistic production and in tool production then these complications pertaining to the peripheral musculoskeletal system and to the medium of activity must be included in the equation.

In summary, if we are to infer the level of general cognitive resources which might be available for proto-language from analysis of hominids' stone tool production routines, then we need to take account of two factors: 1) domain-specific contrasts in the peripheral organization of output in the two types of task, and 2) contrasting aspects of the tasks which relate to the social context in which the skill is practised.

\section{Clinical and experimental methods for resolving these debates}

Wynn $(1991,199)$ has argued that 'there are as yet no well-developed theories of tool behaviour to match those of language'. He proposed a focus on changes in the hierarchical complexity of the constellations 
of knowledge brought to bear on tool production by extinct hominids. From a clinical neuropsychological perspective, Ochipa et al. $(1992,1069)$ have pointed out quite independently that 'the relationship between semantic language impairment and deficits of tool and mechanical knowledge has not been fully investigated'. They suggest that more work on tooluse deficits in clinical brain syndromes would be valuable 'considering the potentially dangerous consequences of the loss of tool and mechanical knowledge' (1992, 1071). It seems sensible for those of us with a theoretical interest in brain function and toolrelated behaviour to build links with clinicians working on the apraxias (and see also Kempler 1993).

In addition, there is clearly more scope for experimental work on tool production and use by normal subjects. Toth's (1985) work on handedness and core rotation is a classic demonstration of this point; and Schick \& Toth (1993) have recently also stated their intention to develop the application of PET scans to localization of cognitive function in tool production. PET scans are invaluable as a guide to focal sites of brain activation (see also Schupp et al. 1994 on imagery and prefrontal EEG), but they are less useful as a monitor of dynamic changes in cortical activation in a sequence of movements. For this, conventional scalp electroencephalography is more useful, and it would be nice to see some EEG studies relating to flint-knapping (if only initially as a test of the method's appropriateness). Additionally, there is plenty of useful work on mental workload which can be done using high-speed video recording of stone tool production. This is being demonstrated by the work of Roux, Bril and colleagues (Roux et al. 1995) on stone bead production in India. We ourselves have initiated a project to quantify the informational complexity of a tool production sequence using Fitts' 'Index of Difficulty' (Fitts 1954). Such experimental and clinical studies will complement the cognitive approach advocated by Wynn. They also have the potential to isolate key contrasts and similarities between tool production and use and linguistic behaviour, on the basis of quantitative indicators of mental workload and of focal sites of brain activation.

For our own work, we have built on the suggestion that there are neuroanatomical associations between the neocortical circuitry regulating speech motor control, and those regulating skilled movements of the hand in object-manipulation tasks (Greenfield 1991; Calvin 1994; Preuss 1995; Wilkins \& Wakefield 1995). Specifically, we follow Wilkins \& Wakefield $(1995,216)$ in speculating that in toolmaking, 'the neurological requirements (relevant to
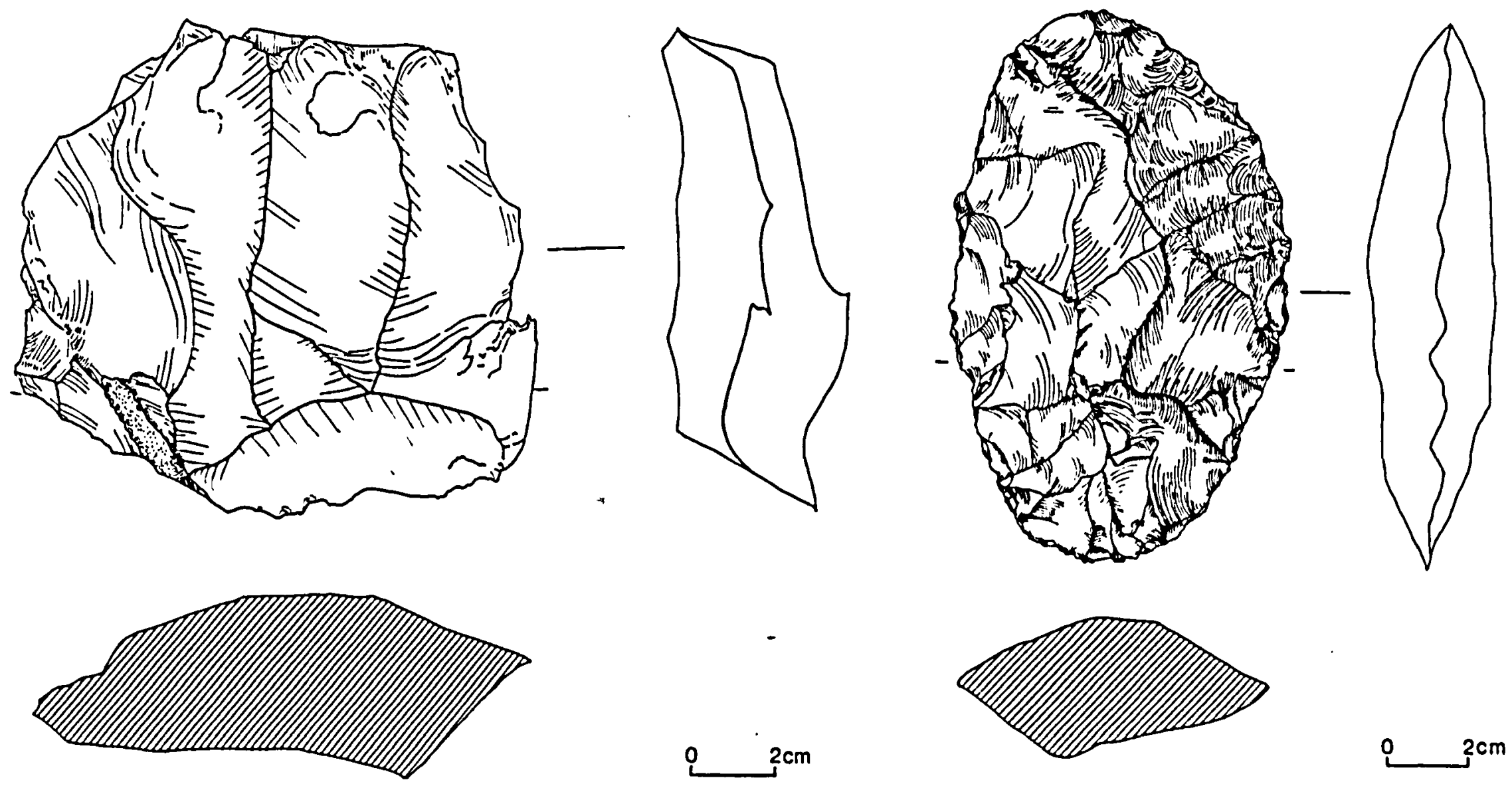

Figure 4. The experimentally replicated stone tools created in the pilot. (i) Clactonian chopper, (ii) Acheulian biface. (Drawings by Sophia Jundi.) 
motor execution, not tool conceptualization) have a direct link with the cognitive requirements for lan-

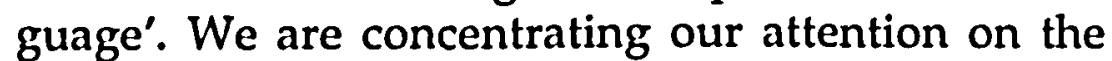
motor organization of the elementary gestural unit in tool-making. For speech, Gracco (1990) has proposed that speech motor organization is hierarchical, with functional output regulated by control of co-ordinated state changes in the entire vocal tract rather than by independent control of each soundproducing element. He suggests that the organizational characteristics of speech as a motor control system are fundamentally similar to other sequential motor actions' $(1990,21)$. We are interested in the co-ordinated movement of whole limbs or limb segments, including precise configurations of the hand, where the demands are high on accuracy, distance and velocity of the movements. By examining the structure of the elementary gesture, we hope to contribute to an understanding of tool-making and its cognitive complexity analogous to results from the study of complexity in motor control at the functional, phonetic level in speech. This may later lead to a better understanding of higher levels of cognitive organization in tool-making, particularly the control of whole reduction sequences by templates, heuristics, or conceptual rules which are the focus of work by Gowlett, Wynn and others.

The pilot phase of our project has involved video recording of two flint-knapping sequences, one for the production of a Clactonian chopper tool, the other for production of an Acheulian biface. For each flakeremoving gesture, the following features have been recorded from videotape for statistical analysis: its distance and duration (to the nearest 0.04 second interval), the position of the knapping arm, and the tool used. These various parameters can be expected to affect the 'information content' of each movement, in the sense of Fitts (1954). Fitts proposed that the difficulty of an aimed movement was a function of the spatial precision required with respect to the target, and the amplitude of the movement. He predicted that as the difficulty of a movement increased (as quantified by this index), so the time taken in execution of the movement should increase correspondingly.

We were interested in these and a number of other parameters. We wanted to see if Fitts' Law held for flint-knapping, so that the more difficult movements took a longer time to complete. We were also interested to find out if there was a positive correlation between the time taken to prepare mentally for execution of a movement, and its difficulty (in Fitts' sense). Thus we recorded the time from the end of the last movement to the inception of the next movement, and classified this as 'preparation time'. Additionally, it was noticed that the experimental knapper rested his elbow on his thigh as a pivot in many knapping movements, effectively eliminating the extra degrees of freedom in control and programming of the upper arm during the planning and execution of these movements. We hypothesized that the extra complexity of movement planning and execution when the elbow was free-moving would be reflected in greater preparation times for execution of such movements. Finally, we speculated that there might be trends detectable across the whole series of gestures in a tool-production sequence, such as decreasing preparation times, owing to 'rehearsal effects' where the motor organization of repeated gestures was substantially similar. The video film was analyzed with these questions in mind.

We report here some results from this pilot

Table 3. Movement distance variability (biface, $n=301$ flake-removing gestures). Mean distance of movement, being the chord of the arc described by the hammer from initial raised position to contact with the striking platform (units are cmis as measured in two dimensions on the television screen, with approximate conversions to original distances).

Tool and arm position:

$\begin{array}{ll}\text { Hammerstone } & 3.32 \\ \text { [elbow free } & 3.40 \\ \text { elbow anchored } & 3.32 \\ \text { Antler } & 6.95 \\ \text { elbow free } & 8.66 \\ \text { elbow anchored } & 3.86 \\ \text { Both hammers, elbow free } & 8.62 \\ \text { Both hammers, elbow anchored } & 3.52\end{array}$

Approx, original distance:

$$
\begin{aligned}
& (\approx 10-11 \mathrm{cms}) \\
& (\approx 10-11 \mathrm{cms}) \\
& (\approx 10-11 \mathrm{cms}) \\
& (\approx 21-3 \mathrm{cms}) \\
& (\approx 26-9 \mathrm{cms}) \\
& (\approx 11-12 \mathrm{cms}) \\
& (\approx 26-9 \mathrm{cms}) \\
& (\approx 10-11 \mathrm{cms})
\end{aligned}
$$

Mean preparation time, secs:

$$
\begin{aligned}
& 2.6 \\
& 0.5] \\
& 2.6 \\
& 2.0 \\
& 2.5 \\
& 1.1 \\
& 2.4 \\
& 2.1
\end{aligned}
$$


study. Using a crude count of the number of flakeremoval gestures for each of the two tool-production sequences, we see at once a contrast in workload: the Clactonian chopper tool took 78 flake-removing strikes to make, over a period of six minutes, while the Acheulian biface took 301 such strikes over 24 minutes (strike counts excluding platform preparation and platform abrasion). Within the series of gestures involved in the Acheulian biface sequence, there was a progression in choice of hammer and in associated motor control requirements. Arbitrarily dividing the sequence into two consecutive halves by 'strike number', we find that flake-removing gestures in which the hammerstone was used occurred only in the first half of the series, while antler was used throughout the second half of the series ( 85 per cent of all antler use was in the latter half of the sequence). Of the 112 hammerstone gestures, all but one were made with the elbow resting or pivoting on the knapper's thigh. Of the 188 soft hammer gestures, 121 were made with the elbow moving freely; the remaining 67 involved the elbow resting or pivoting on the knapper's thigh. This contrast is statistically significant $\left(X^{2}=118,1\right.$ d.f. $\left.{ }^{* *}\right)$. It also correlates with differences in the distance of movement: the gestures made using the antler, and with the elbow moving freely, made the hammer travel furthest (distance from the initial raised-arm position to the striking platform) (see Table 3 ).

For the movements involving the antler hammer (the more complex gestures in motor terms) we observed patterning in the relationship between preparation time and distance. We also saw a residual effect of the place of the blow in the whole series which may reflect a 'rehearsal effect'. With respect to Fitts' 'Index of Difficulty', flake-removal gestures travelling greater distances seem to have been made with increased velocities, and thus to have been substantially more 'difficult' (Table 4, equation 1), but the frame interval on the video film (0.04 sec.) proved too coarse for further examination of this factor. The regression equations and correlation coefficients given in Table 4 demonstrate the posi- tive effect of distance travelled by the hammer on preceding preparation time (equation 2), and the negative residual effect on preparation time (controlled for distance of the ensuing movement) of position in the whole knapping series (equation 3 ). Antler hammer strikes made with the elbow anchored and with it moving freely differed significantly for distance, duration and preparation time. The gestures with free-moving elbow had the greater mean value for each variable. Overall, we interpret these results as indicating regularities in motor-programming relating respectively a) to the complexity of coordination of muscle groups in greater-distance movements, and b) to the facilitating effect of repetition of similar movements on preparation of later movements in a series. Even for the greater-distance gestures, however, these effects are not especially strong, and it is apparent that other factors influence the time elapsed in the build-up to one of these ballistic arm movements - notably variance in inspection times during the evaluation of a partiallyreduced core while decisions are being made about where to strike the next blow. It is these other factors which may best indicate activation of the prefrontal areas of the brain, and thus identify the most complex levels of intentional behaviour manifested in such a sequence of actions.

The preparation time prior to strikes was, on average, of the order of 1-3 seconds across the whole biface sequence. The discovery that this preparation time is causally related to the motor-complexity of the ensuing knapping gesture indicates that these gestures impose substantially greater mental workloads than the preparation of vocal tract configurations in the elementary phonetic units of speech. We have already given reasons why this should be so. Clearly, searches for analogies between tool-making and speech need to take account of these contrasts in the peripheral organization of motor output. We believe that this is as productive a level at which to engage with such questions, as are the more abstract levels relating to spatial cognition or to the 'grammar' of material culture.

Table 4. Patterns in use of the antler hammer ( $n=188$ flake-removing gestures). Significance level ${ }^{* * *}=p<0.001$.

Ln Velocity (i.e. Distance/Duration) $=0.79$ (ln Distance) -1.83

Ln Preparation time (secs.) $=0.77$ (In Distance) -1.2

$$
\begin{aligned}
& r=0.93^{* * *} \\
& r=0.50^{* * *} \\
& r=-0.35^{* * *}
\end{aligned}
$$

Note: 'Preparation time' is the time elapsed from the completion of the preceding strike or platform abrading movement, to the inception of another strike. 


\section{Conclusions}

In this article, we have argued that in many fundamental respects manipulative behaviour and language processes are analogous. We have also shown how the evolutionary anatomy of the human brain supports this argument. The current focus in cognitive psychology on domain-specific mechanisms will supply valuable correctives to older models of hominid brain evolution, many of which stressed the interpretation of the human brain as an adaptation for flexible generalists. It is also important, however, to remain aware of the developmental constraints on primate brain evolution. There remains plenty of scope for extended allometric analyses of the functional components of the human and primate brains as a basis for extrapolating back to the cognitive abilities of extinct species of hominid. In addition, clinical neuropsychology has much to offer to help us understand the functional organization of tool production and use, at the level of the neocortex. Finally, close analysis of the psychophysiology and motor organization of stone tool-making in modern flint-knappers will provide an independent control on this clinical evidence. It will also give some indication of the mental workload involved in producing tools of the various types found in the Palaeolithic record. In addition to the intrinsic interest of such studies, they will have an extra value in adding to our understanding of parallels and divergences between the cognitive and motor organization of manipulative tool behaviour and speech. These will help resolve the question of the chronology of proto-language evolution.

\section{Acknowledgements}

We are very grateful to Charles Cunningham (Department of Psychology, University of Southampton) for videotaping the knapping sequences and editing them with clock and grid overlays for subsequent analysis. Responsibility for the literature review, synthesis and experimental design lies with the senior author (J.S.). The flint-knapping was carried out by F.W-S., and recording of temporal and spatial information about the sequences (from videotape) by A.Q.. Drawing of the experimental replica tools was by Sophia Jundi.

\section{Notes}

1. The sample of behavioural creativity is from a very small number of zoo animals (2-4 individu- als of each species), each sampled for a single 45 minute period, uncontrolled for differences in rearing history or extent of enrichment of cage environment. What is remarkable, given this data quality, is that such a correlation should be observable at all.

2. Arguments for the dissociation of tool use and language have drawn on other evidence than that of the relative roles of visuospatial cognition and motor sequencing. Wynn (1991) has argued that motor organization of manual skills is acquired by rote learning of elementary components which are then chained into action sequences. He contrasts this with the effortless pattern of language acquisition. The most appropriate analogy for the types of motor-skill learning discussed at greatest length by Wynn is, however, adult second language acquisition or foreign language learning, not primary language acquisition. The purse seine netters and smiths he discusses are cases of specialized adult apprenticeship, and these processes follow a rather different course to primary language development. In second language acquisition, negative evidence (correction of errors) plays a much more important role than in primary language acquisition. There is a parallel here with the role of 'knowledge of results' in motor skill acquisition (cf., respectively, Gass 1990 and Adams 1987). Appropriate analogies to primary language acquisition must come from studies of children's cognitive development in object manipulation and their motor skill development in complex movement tasks (e.g. Greenfield 1991; Thelen 1991). Additionally, given the social nature of language, if we want to look at parallels to second language learning in motor skill learning, we should probably concentrate on dyad interactions in co-operative or adversarial sports like dance, acrobatics or fencing and observe the extent to which acquisition of a repertoire of actions follows stable sets of rules relating to the rhythmic, speech-like turntaking which such activities demand.

James Stecle, Angus Quinlan \& Francis Wenban-Smith Department of Archaeology University of Southampton Highifield Southampton SO17 1BJ 


\section{References}

Adams, J.A., 1987. Historical review and appraisal of research on the learning, retention, and transfer of human motor skills. Psychological Bulletin 101, 41-74.

Annett, J., 1993. The learning of motor skills: sports science and ergonomics perspectives. Ergonomics 37, 5-16.

Armstrong, E., K. Zilles \& A. Schleicher, 1993."Cortical folding and the evolution of the human brain. Journal of Human Evolution 25, 387-92.

Bellugi, U., A. Bihrle \& D. Corina, 1991. Linguistic and spatial development: dissociations between cognitive domains, in Biological and Belavioral Determinants of Language Development, eds. N.A. Krasnegor, D.M. Rumbaugh, R.L. Schiefelbusch \& M. StuddertKennedy. Hillsdale (NJ): Lawrence Erlbaum, 363-93.

-Bradley, B. \& C.G. Sampson, 1986. Analysis by replication of two Acheulian artefact assemblages from Caddington, England, in Stone Age Prelistory, eds. G.N. Bailey \& P. Callow. Cambridge: Cambridge University Press, 29-45.

Bril, B., 1991. Les gestes de percussion: analyse d'un mouvement technique, in Savoir Faire et Ponvoir Transmettre, ed. D. Chevallier. Paris: Editions de la Maison des Sciences de l'Homme, 61-80.

Brodmann, K., 1912. Ergebnisse über die vergleichende histologische Lokalisation der Grosshirnrinde mit besonderer Berücksichtigung des Stirnhirns. Anatomische Anzeiger (Suppl.) 41, 157-216.

Calvin, W.H., 1994. The emergence of intelligence. Scientific American 271(4), 79-85.

Clarke, A.S. \& S. Boinski, forthcoming. Temperament and responsivity in nonhuman primates. American Journal of Primatology, submitted.

Cromer, R.F., 1974. The development of language and cognition: the cognition hypothesis, in New Perspectives in Child Development, ed. B. Foss. Harmondsworth: Penguin, 184-252.

Cromer, R.F., 1991. Language and Thought in Normal and Handicapped Children. Oxford: Blackwell.

Daigneault, S., C.M.J. Braun \& H.A. Whitaker, 1992. An empirical test of two opposing theoretical models of prefrontal function. Brain and Cognition 19, 48-71.

de Lacoste, M.-C. \& D.J. Woodward, 1988. The corpus callosum in nonhuman primates. Brain, Behnviour and Evolution 31, 318-23.

De Renzi, E. \& F. Lucchelli, 1988. Ideational apraxia. Brain $111,1173-85$.

Deacon, T.W., 1988. Human brain evolution: I. Evolution of language circuits, in Intelligence and Evolutionary Biology, eds. H. Jerison \& I. Jerison. Berlin: Springer, 363-81.

Finlay, B.L. \& R.B. Darlington, 1995. Linked regularities in the development and evolution of mammalian brains. Science 268, 1578-84.

Fitts, P.M., 1954. The information capacity of the human motor system in controlling the amplitude of movement. Journal of Experimental Psychology 47, 381-91.

Fox, P., S. Petersen, M. Posner \& M. Raichle, 1988. Is Broca's area language specific? Neurology 38 (Suppl. 1), 172.

Gass, S.M., 1990. Second and foreign language learning: same, different or none of the above, in Second Language Acquisition - Foreign Language Learning, eds. B. VanPatten \& J.F. Lee. Clevedon, Philadelphia (PA): Multilingual Matters Ltd, 34-44.

Gibson, K.R., 1990. New perspectives on instinct and intelligence: brain size and the emergence of hierarchical mental constructional skills, in 'Language' and Intelligence in Monkeys and Apes: Comparative Developmental Perspectives, eds. S.T. Parker \& K.R. Gibson. Cambridge: Cambridge University Press, 97-128.

Goldman-Rakic, P.S., 1987. Motor control function of the prefrontal cortex, in Motor Areas of the Cerebral Cortex, eds. G. Bock, M. O'Connor \& J. Marsh. (Ciba Foundation Symposium 132.) Chichester: Wiley, 187-200.

Gowlett, J.A.J., 1986. Culture and conceptualisation: the Oldowan-Acheulian gradient, in Stone Age Prelistory, eds. G.N. Bailey \& P. Callow. Cambridge: Cambridge University Press, 243-60.

Gracco, V.L., 1990. Characteristics of speech as a motor control system, in Cerebral Control of Speech and Limb Movements, ed. G.R. Hammond. Amsterdam: NorthHolland, 3-28.

Greenfield, P.M., 1991. Language, tools and the brain: the ontogeny and phylogeny of hierarchically organized sequential behavior. Behavioral and Brain Sciences 14, 531-95.

Haaland, K.Y. \& D.L. Harrington, 1994. Limb-sequencing deficits after left but not right hemisphere damage. Brain and Cognition 24, 104-22.

Harvey, P.H., R.D. Martin \& T.H. Clutton-Brock, 1987. Life histories in comparative perspective, in Primate Societies, eds. B.B. Smuts, D.L. Cheney, R.M. Seyfarth, R.W. Wrangham \& T.T. Struhsaker. Chicago (IL): University of Chicago Press, 181-96.

Hirschfeld, L.A. \& S.A. Gelman, 1994. Toward a topography of mind: an introduction to domain specificity, in Mapping the Mind, eds. L.A. Hirschfeld \& S.A. Gelman. Cambridge: Cambridge University Press, 3-35.

Holloway, R.L., 1983. Human paleontological evidence relating to language behavior. Humman Neurobiology 2, 105-14.

Ingvar, D.H., 1994. The will of the brain: cerebral correlates of willful acts. Journal of Theoretical Biology 171, 7-12.

Isaac, G.Ll., 1976. Stages of cultural elaboration in the Pleistocene: possible archaeological indicators of the development of langunge capabilities. Amals of the New York Academy of Sciences 280, 275-88.

Jerison, H.J., 1988. Evolutionary biology of intelligence: the nature of the problem, in Intelligence and Evolintionary Biology, eds. H. Jerison \& I. Jerison. Berlin: Springer, 1-11.

Kempler, D., 1993. Disorders of langunge and tool use: neurological and cognitive links, in Tools, Langunge and Cognition in Human Evolution, eds. K.R. Gibson \& T. Ingold. Cambridge: Cambridge University Press, 193-215. 
McHenry, H.M., 1994. Tempo and mode in human evolution. Proceedings of the National Academy of Science (USA) 91, 6780-86.

Markowitsch, H.J., 1988. Anatomical and functional organization of the primate prefrontal cortical system, in Comparative Primate Biology, vol. 4: Neurosciences, eds. H.D. Steklis \& J. Erwin. New York (NY): Alan R. Liss, 99-153.

Nudo, R.J. \& R.B. Masterson, 1990. Descending pathways to the spinal cord 4 . The amount of cortex devoted to the corticospinal tract. Journal of Comparative Neurology 296, 584-97.

Ochipa, C., L.J.G. Rothi \& K.M. Heilman, 1989. Ideational apraxia: a deficit in tool selection and use. Ammals of Neurology 25, 190-93.

Ochipa, C., L.J.G. Rothi \& K.M. Heilman, 1992. Conceptual apraxia in Alzheimer's disease. Brain 115, 1061-71.

Parker, C.E., 1974. Behavioral diversity in ten species of nonhuman primates. Journal of Comparative and Plusiological Psychology 87, 930-37.

Passingham, R.E., 1982. The Human Primate. Oxford: Freeman.

Passingham, R.E., 1987. Two cortical systems for directing movement, in Motor Areas of the Cerebral Cortex, eds. G. Bock, M. O'Connor \& J. Marsh. (Ciba Foundation Symposium 132.) Chichester: Wiley, 151-64.

Passingham, R.E., C.A. Heywood \& P.D. Nixon, 1986. Reorganization in the human brain as illustrated by the thalamus. Brain, Belaviour and Evolution 29, 68-76.

Pelegrin, J., 1990. Prehistoric lithic technology: some aspects of research. Arcliacological Review from Cambridge 9(1), 116-25.

Pinker, S. \& P. Bloom, 1990. Natural language and natural selection. Belanviornl and Brain Sciences 13, 707-84.

Preuss, T.M., 1995. The argument from animals to humans in cognitive neuroscience, in The Cognitive Neurosciences, ed. M.S. Gazzaniga. Cambridge (MA): M.I.T. Press, $1227-41$.

Ringo, J.L., 1991. Neuronal interconnection as a function of brain size. Brain, Belnaviour and Evolution 38, 1-6.

Ringo, J.L., R.W. Doty, S. Demeter \& P.Y. Simard, 1994. Time is of the essence - a conjecture that hemispheric specialization arises from interhemispheric conduction delay. Cerebral Cortex 4, 331-43.

Robin, N. \& K.J. Holyoak, 1995. Relational complexity and the prefrontal cortex, in The Cognitive Neurosciences, ed. M.S. Gazzaniga. Cambridge (MA): M.I.T. Press, 987-97.

Roux, V., B. Bril \& G. Dietrich, 1995. Skills and learning difficulties involved in stone knapping: the case of stone bead knapping in Khambat, India. World Archacology 27(1), 63-87.

Schick, K.D. \& N. Toth, 1993. Making Silent Stones Speak: Human Evolution and the Daron of Technology. New York (NY): Simon and Schuster.

Schupp, H.T., W. Lutzenberger, N. Birbaumer, W. Miltner \& C. Braun, 1994. Neurophysiological differences between perception and imagery. Cognitive Brain Research 2, 77-86.

Steele, J., in press. On the evolution of temperament and dominance style in hominid groups, in The Archaeology of Human Ancestry: Power, Sex and Tradition, eds. J. Steele \& S. Shennan. London: Routledge.

Thelen, E., 1991. Motor aspects of emergent speech: a dynamic approach, in Biological and Behavioral Determinants of Language Development, eds. N.A. Krasnegor, D.M. Rumbaugh, R.L. Schiefelbusch \& M. Studdert-Kennedy. Hillsdale (NJ): Lawrence Erlbaum Associates, 339-62.

Toth, N., 1985. Archaeological evidence for preferential right-handedness in the Lower and Middle Pleistocene, and its possible implications. Journal of Human Evolution 14, 607-14.

Wilkins, W.K. \& J. Wakefield, 1995. Brain evolution and neurolinguistic preconditions. Behnvioral and Brain Sciences 18, 161-226.

Wynn, T., 1989. The Evolution of Spatial Competence. Urbana (IL): University of Illinois Press.

Wynn, T., 1991. Tools, grammar and the archaeology of cognition. Cambridge Archaeological Journal 1(2), 191206.

Yerkes, R.M. \& A.W. Yerkes, 1929. The Great Apes: a Study of Anthropoid Life. New Haven (CT): Yale University Press.

Yeterian, E.H. \& D.N. Pandya, 1988. Architectonic features of the primate brain: implications for information processing and behavior, in Information Processing by the Brain, ed. H. Markowitsch. Toronto: Hans Huber, 7-38. 